\title{
Toward Reconciliation: What do the Calls to Action Mean for Early Childhood Education?
}

\author{
Briony Taylor
}

Briony Taylor lives in Vancouver and is in her second year of the ECCE degree program at Capilano University. Email: briony. taylor@gmail.com

This article focuses on how the Truth and Reconciliation Commission (TRC) of Canada's Calls to Action pertain to early childhood education. The author, who is a student and soon to be educator, traces her understanding of reconciliation within early childhood spaces by considering the TRC call to develop culturally appropriate Aboriginal early childhood education programs. Incorporating her recent learning, she explores curriculum, language, parents, community, and treaty relationships. She questions her own previously held assumptions around dominant discourses of success and reflects on new understandings of reconciliation gained in her program of study.

Keywords: Truth and Reconciliation Commission; calls to action; Indigenous/Aboriginal early childhood education; British Columbia

self-actualization and self-worth for Aboriginal youth" (p. 231). I believe we all have a role to play in reconciliation.

As a student and soon to be early childhood educator in British Columbia, the act of reconciliation is on my mind. We, as settlers living on the traditional lands of Aboriginal peoples ${ }^{11}$, may be a generation removed from acts of colonialism and cultural genocide, yet we live with the benefits of this shared history. My earlier education did not teach me to be aware of the degree to which these benefits have harmed Aboriginal peoples, and it was only in my postsecondary studies that I began to become aware of it. I am learning about the atrocities committed against the Aboriginal peoples of North America, specifically the residential schools of Canada. At the same time, I am aware and recognize that most non-Aboriginal people, myself included, will probably never be able to understand deeply the impact of having one's land and culture stolen. As an early childhood educator, I want to be able to promote social justice in the classroom with colleagues, families, and children. What follows is my exploration of two sections in particular of the Truth and Reconciliation Commission of Canada's (2015) Calls to Action and some of the ways that I have been learning to and hope to pursue reconciliation within the early childhood field. As Mai Nguyen (2011) writes, "early Aboriginal childhood education is crucial in the development of

\section{Background}

In 2008, the Truth and Reconciliation Commission (TRC) arose out of a mandate of the Indian Residential Schools Settlement Agreement of 2007. In 2015, the TRC put forth 94 calls to action "to redress the legacy of residential schools and advance the process of Canadian reconciliation (p. 1). Call \#12 speaks to early childhood education: "We call upon the federal, provincial, territorial, and Aboriginal governments to develop culturally appropriate early childhood education programs for Aboriginal families” (p. 2).

The call is specifically directed toward multiple levels of government to develop the programs; however, as an engaged citizen and future educator working toward reconciliation, I feel that it is important for me to consider what culturally appropriate means. As a nonAboriginal educator, I will embrace this call in a number of ways. Throughout my studies in early childhood education, an idea has been recurring. Prior to studying ECE, I would not have understood or been exposed to the idea of a pedagogy of listening, that is, listening to children with all of our senses (Rinaldi, 2012). I realize that it is through relationships and dialogue with families and colleagues and a pedagogy of listening that I will work toward reconciliation in the space of early childhood education. In addition, the TRC's calls to action provide a framework for thinking about my work in British Columbia. As I consider this extensive call to action, \#12, I take inspiration from an earlier call to action, \#10:

1 In this article, I use the term Aboriginal peoples to refer to the Indigenous peoples of Canada in order to maintain language that is consistent with the Truth and Reconciliation Commission of Canada: Calls to Action. 
10. We call on the federal government to draft new Aboriginal education legislation with the full participation and informed consent of Aboriginal peoples. The new legislation would include a commitment to sufficient funding and would incorporate the following principles:

i. Providing sufficient funding to close identified educational achievement gaps within one generation.

ii. Improving education attainment levels and success rates.

iii. Developing culturally appropriate curricula.

iv. Protecting the right to Aboriginal languages, including the teaching of Aboriginal languages as credit courses.

v. Enabling parental and community responsibility, control, and accountability, similar to what parents enjoy in public school systems.

vi. Enabling parents to fully participate in the education of their children.

vii. $\quad$ Respecting and honouring Treaty relationships. (Truth and Reconciliation Commission of Canada, 2015, p. 2)

While call \#10 speaks to education at the kindergarten to grade 12 level, it would be beneficial to embrace some of its principles within early childhood education. In particular, there are four principles from call \#10 that I will consider in relation to call \#12. These principles are (iii) developing culturally appropriate curricula, (iv) protecting the right to Aboriginal languages, (vi) enabling parents to fully participate in the education of their children, and (vii) respecting and honouring Treaty relationships. These principles align with the philosophy of British Columbia's Early Learning Framework (Government of British Columbia, 2008). For example, the provincial framework, which I will be following as an early childhood educator, states: "As many Aboriginal communities revitalize their languages, cultures, and traditions, the development of children's cultural identity is considered a top priority in early learning" ( $p$. 8). Given the direction of these two documents, I want to be familiar with specific ways to pursue reconciliation.

\section{Culturally Appropriate Curricula: Child Autonomy}

What do culturally appropriate Aboriginal early childhood education programs look like? Philosophically, it means we should endeavour to gain an understanding of an Aboriginal view of childrearing. For example, Muir and Bohr (2014) explain that the Aboriginal view of the child may be different from dominant Western views of children, thus childrearing practices may be different. Child autonomy is valued, as is a respectful attitude toward the child: "Aboriginal children are openly recognized and respected as persons and are thus encouraged to make their own decisions about how they wish to explore their environment" (p. 70). Children become independent by making their own decisions, a move that promotes democracy and engagement. A culturally appropriate curriculum needs to respect children and have a healthy level of child autonomy when it comes to teaching and learning. In this view of the child as capable, it is also important to recognize the child's existing life experiences and knowledge. Madeleine MacIvor (1995) writes: "One way to respect this personal power and autonomy is to recognize and honour the knowledge and skills children bring with them into the classroom. Aboriginal students bring rich and varied experiences with them, and educators have been recommended to use this [background]" (p. 82). MacIvor's statement leads me to think about a number of questions. How do we know what skills children bring with them? Are we committed to a philosophy of attunement? That is, are we working in harmony with children? Do we take enough time to get to know children? As I have been learning in my coursework and practicum, children construct knowledge together. The more variety in the knowledge base, the more children teach each other and teach us as educators. Moreover, with an attitude of respect and humility, inviting families to participate will be a practical step toward building authentic relationships and deepening our understanding of what it means to honour the children's knowledge and skills. 


\section{Culturally Appropriate Curricula: Health and Nutrition}

Health and nutrition are important components of ECE programs. Provincial licensing requirements state that we must "ensure that each child has healthy food and drink according to the Canada Food Guide" and "promote healthy eating and nutritional habits" (Government of British Columbia, 2007, sec. 48.1). In meeting the call to provide culturally relevant curricula, food is a significant component. Many remote Aboriginal communities face the struggle of food security. Packed and highly processed foods are financially prohibitive, while on the other hand, traditional foods are seasonally available. By incorporating traditional foods into ECE programs, Elders and knowledge holders can share stories about traditional foods:

\section{Elders enjoy teaching others about their food customs since their childhood memories about hunting or collecting, preparing and sharing foods with family usually remain vivid with tastes and smells and good feelings. These occasions often provide opportunities for also sharing songs that accompany berry picking or hunting, and stories of rituals and celebrations that marked a child's growing up. (Aboriginal Head Start Association of British Columbia, 2012, para. 5)}

I remember a time when I was a student volunteer at an Inuit children's centre. For many of the families, living in the south meant that northern foods were hard to find. Since the centre was composed of such a large community of people, staff members were able to coordinate a community dinner of caribou, with blubber used for the qulliq, a traditional lamp. In British Columbia, more information on traditional foods can be found online through the First Nations Health Council. While it may be difficult to provide traditional foods like caribou in centres that are not near Aboriginal communities, smaller, more easily accessible foods, such as berries or roots, can be prepared alongside families. When traditional foods are incorporated into the curriculum, it is important to consider the opportunities of evenings and weekends to bring families together to share in traditional meals. We may have to ask ourselves if our programs allow for such flexibility. And, if they do, are we comfortable forming reciprocal relationships?

\section{Culturally Appropriate Curricula: Artistic Explorations}

My academic program of study places great value on the arts. In experiencing how a studio functions and catching glimpses of how the atelierista (an educator with background in the arts) is a vital part of an early childhood centre, I want art to be a vital part of my work and the life of the childcare centre in which I work. From a healing perspective, culturally relevant curricula could incorporate opportunities to use arts and crafts to engage children and their parents in a healing process. For example, the Inspir=ed project in Australia has taken this approach. Australian educators Hanckel and Segal (2016) state that "arts activities have been widely documented in helping children deal with trauma" (p. 14). Parents join together with their children in "painting, beeswax modeling, and creating with natural materials"; later, parents join with other parents to participate in group "basket weaving, simple doll making, knitting, crocheting, felting, and wood carving" (Hanckel \& Segal, 2016, p. 14). Parents learn new skills and become producers, rather than only consumers, of materials such as toys. In these circles parents come together to talk about their feelings and share their perspectives. In the Canadian context, Elders could join these healing circles, share their knowledge, and create a safe space for parents, educators, and the community as a whole to learn together, share stories of children's competence, and heal from the legacy of residential schools and colonization.

\section{Protecting the Right to Aboriginal Languages}

The principle of protecting the right to Aboriginal languages also supports TRC call \#12, the call for culturally appropriate ECE programs. There are over sixty Aboriginal languages in Canada and dialects within languages. When Aboriginal children are exposed to their heritage language, it helps in the formation of their identity and their connection to their land (Ball, 2009). When possible, the teaching, learning, and speaking of Aboriginal languages needs to be embraced so that children can be exposed to and exist in an environment that supports their Aboriginal language. Upholding this principle may present more challenges in regions where licensed educators with knowledge and comfort speaking their heritage language is rare. This is why community members are so important as partners in early childhood centres. As Jessica Ball (2009) argues, community members are "uniquely positioned to identify core features of language socialization, to understand the contexts of child development and care in the community and to offer insights to specialists, educators and investigators about the conditions, needs and goals of a family" (p. 41). In nonurban centres or places that are located near First Nations communities, language nest programs are sometimes offered; these are early years childcare programs run entirely in the community's Aboriginal language. Developmental psychology tells us that by the age of 3, "most children are putting together multiword sentences" (Levine \& Munsch, 2014, p. 305). As educators, we need to make diligent efforts to support children's right to be educated in their language. This efforts can include purchasing books, learning key words and phrases, and when possible, 
inviting Elders and children's family members to share stories in the children's languages. The right to Aboriginal languages means the right to transmit language from one generation to another.

\section{Parents as Participants}

Enabling parents to fully participate in the education of their children is a vital principle that supports the development of culturally appropriate ECE programs (Truth and Reconciliation Commission of Canada, 2015, p. 2). This important TRC call to action is challenging for Aboriginal and non-Aboriginal communities alike. In working toward meeting this call, cultural compatibility theory is a valuable lens with which to view education. Preston, Cottrell, Pelletier, and Pearce (2011) write that

central to cultural compatibility theory is the principle of congruence-the belief that when values and expectations of the classroom are harmonious with those of the school community, student participation and learning improves ... [Further,] when a child is immersed in an educational environment that is culturally compatible with the values of the community, learning prospects are improved. (p. 7)

When I reflect on the idea of improving learning prospects, I caution myself to remember that this is not the same as what we think of as school success. After all, who gets to define school success? And how is it defined? How does it connect to success in life? In contrast to mainstream ideas of school success, learning prospects grow because what is learned is relevant to everyday lived experiences. In working toward reconciliation, centres should be inviting families to participate so that the values of the families are reflected in the environment in which the child learns and grows. Moreover, it is important to acknowledge that Aboriginal peoples highly value the extended family, while dominant discourses tend to value the nurture and attachment of a sole caregiver, primarily the mother, within the nuclear family. The extended family plays an active role in raising the child in Aboriginal cultures; the community as a whole is responsive to the child (Muir \& Bohr, 2014). It is important for educators to understand cultural differences as well as family diversity so that assumptions are not made about children, parents, and families. When the school or centre collaboratively engages with families to understand important family knowledge and teachings, we validate Aboriginal truths and ways of knowing, and we move closer toward reconciliation.

\section{Parents and Inclusive Education}

Developmental psychology deeply influences early childhood development experts. This influence is seen in academic literature and in early childhood education policy. When educators are working with a team of specialists to support children with individual education plans, it is important that educators think critically about the assessments and interventions that are undertaken. In the report Aboriginal Early Childhood Development Assessment: Issues and Insights in a Cultural Context written for the British Columbia Aboriginal Child Care Society, educators are called to "support approaches that are more reflective of the traditions and values of Aboriginal communities" and to value "cultural and linguistic flexibility, cultural competence, professional sensitivity and reflective practice, empowerment, and strengths based approaches" (BC Regional Innovation Chair for Aboriginal Early Childhood Development, 2013, p. 25). To support my learning, I have been volunteering at a local preschool. One practice stands out: the way in which educators support children with special rights. Without disclosing confidential details, the educators I have been working with shared with me the parents' goals for their children. This has been very helpful in our work as a team and a community. As educators, we must recognize that families should have a greater involvement in these plans and that our Western knowledge of development is only one way of approaching child development. Moreover, when reading Glenda MacNaughton (2005), I learned that "it has been argued that in the early childhood field, child development knowledge has become a regime of truth in that it regulates and governs what is the appropriate or correct way to understand and organize young children" (p. 33). I am reminded that we must question our assumptions and prevent practices that have marginalized Aboriginal children and families. By working in dialogue with families, we will gain understanding of their goals for their children.

\section{Inviting Community Participation}

TRC call to action \#12 is a call to develop culturally appropriate ECE programs. In addition to the principle of enabling parent participation, we should also invite and welcome community participation. As Nguyen (2011) writes, "levels [of lower employability] can be attributed to the exclusion of Aboriginals from the education policy process, beginning with its creation all the way to the implementation of education policy" (p. 244). It is detrimental to Aboriginal communities when communities are not included as active 
participants in the ongoing development of culturally appropriate early childhood education. Call \#12 encourages educators in the field to invite communities to participate. And, when communities do participate, the call to educators is to humbly embrace the partnership. In accepting that our knowledge is partial, we employ a pedagogy of listening. Carla Rinaldi (2012) shares that "the task of those who educate is not only to allow ... differences to be expressed but to make it possible for them to be negotiated and nurtured through exchanging and comparing ideas" (p. 237). Centres are responsible to the community, thus the community should have some level of control over the centre and the centre should be accountable to the community. What this looks like may be different from location to location. On-reserve childcare centres may receive most of their input from the local First Nation, while off-reserve or urban centres may receive a variety of input, including from the dominant cultural community and diverse groups of Aboriginal peoples.

One way of encouraging and moving toward culturally appropriate ECE is to work toward inviting the community to have a presence in the childcare centre. The Strengthening Families Initiative, based in Illinois, runs Parent Cafés. An event is organized where parents lead discussions, learn from each other at various tables, and help one another wrestle with tough questions. Jor'dan, Wolf, and Douglass (2012) write that these cafés "are led by parents, for parents, which is what makes them meaningful" (p. 21). An event like this could be used to invite community members to participate in the decision-making life of childcare centres in Canada. Cafés or other events could be held at the start of the year and throughout the year. Different Elders and community leaders could host the various tables. Community members are the ones generating questions and answers and collectively supporting one another through dialogue. This is one possible way for local Aboriginal communities to share responsibility, control, and accountability for culturally appropriate programs.

\title{
Respecting and Honouring Treaty Relationships
}

What does it mean to honour treaty relationships in early childhood education? As a starting point, settler Canadians need to acknowledge that many Aboriginal peoples have negotiated treaty relationships with the Canadian government. A treaty is a formal, ratified agreement between nations. Each treaty sets out "promises, obligations and benefits for both parties" (Government of Canada, 2010). Sheila CarrStewart (2001) writes of the importance of education as a treaty right:

\begin{abstract}
Reflecting recent rulings of the Supreme Court of Canada, the Royal Commission on Aboriginal Peoples recommended the recognition of education as a treaty right. Furthermore, the Royal Commission stated First Nations "want two things from education ... the skills they need to participate fully in the economy ... [along] with the knowledge of their languages and traditions necessary for cultural continuity" (RCAP, 1996a, p. 82), a goal similar to what the chiefs and headmen believed they had negotiated as a treaty right to education. (p. 141)
\end{abstract}

As educators, we need to recognize that education is a treaty right. We honour treaty relationships when we acknowledge this right. Early childhood education centres may be located on lands with negotiated treaties, as much of eastern Canada is, while other centres may be located on unceded traditional territories of local Aboriginal peoples. We need to acknowledge the people and their lands. While education, including early childhood education, is regulated and provided to settler Canadians by their provincial governments, we need to be aware that the federal government is obligated to provide education funding and programming, as well as other services, to Aboriginal peoples. First Nations negotiate nation-to-nation relationships with the federal government. Educators who take seriously the care component of their field need to stay current with the culturally affirming programs, services, and initiatives that are offered by Aboriginal organizations. For example, in British Columbia, health services provided to First Nations living on reserve are managed by the First Nations Health Authority. Becoming familiar with such services provides educators with a more holistic understanding of the early years and exposes them to diverse ways of knowing.

\section{Conclusion}

The Truth and Reconciliation Commission has put forth 94 calls to action to "redress the legacy of residential schools and advance the process of Canadian reconciliation" $(2015$, p. 2). As a future early childhood educator, call \#12 speaks to me personally and professionally. While I realize this call is directed toward four different governments, I also know that I have a role to play in supporting culturally appropriate ECE programs. By adopting principles from call \#10, I will be mindful of promoting culturally appropriate curricula, protecting the right to Aboriginal languages, enabling parent participation, and respecting and honouring treaty relationships.

Cultural advisor Shelley Joseph from Reconciliation Canada, in her compelling keynote address to the Capilano University community, told us that we all have a role to play in reconciliation and for many of us that means taking the time to listen to each other (S. 
Joseph, keynote address, September 23, 2016). The Truth and Reconciliation Commission's calls to action are important to the early childhood education field as we seek to work in and toward culturally appropriate ECE programs for children, families, communities, and educators. We must each listen to what these calls mean to us, both personally and professionally, and work together to move forward as a community toward reconciliation.

\section{References}

Aboriginal Head Start Association of British Columbia. (2012). Tips and tools for nutrition awareness. Retrieved from: http://www. ahsabc.com/index.php/tips-tools/for-nutrition-awareness

Ball, J. (2009). Aboriginal young children's language development: Promising practices and needs. Canadian Issues, Winter, 37-43.

BC Regional Innovation Chair for Aboriginal Early Childhood Development. (2013). Aboriginal early childhood development assessment: Issues and insights in a cultural context. Retrieved from: https://www2.viu.ca/chairaecd/documents/ ChildDevelopmentScreeningandAssessment_2013.pdf

Carr-Stewart, S. (2001). A treaty right to education. Canadian Journal of Education, 26(2), 125-143.

Government of British Columbia. (2007). Child care licensing regulation. Victoria, BC: Queen’s Printer.

Government of British Columbia. (2008). British Columbia early learning framework. Victoria, BC: BC Ministry of Health, BC Ministry of Children and Family Development, \& BC Early Learning Advisory Group.

Government of Canada. (2010). Treaties with Aboriginal people in Canada. Retrieved from http://www.aadnc-aandc.gc.ca/ eng/1100100032291/1100100032292

Hanckel, J., \& Segal, L. (2016). The Inspire=ed project: A holistic early childhood program for enhancing parent-child well-being. Childhood Education, 92(1), 10-21.

Jor'dan, J. R., Wolf, K. G., \& Douglass, A. (2012). Increasing family engagement in early childhood programs. Young Children, 67(5), $18-23$.

Levine, L. E., \& Munsch, J. (2014). Child development: An active learning approach (2nd ed.). Los Angeles, CA: SAGE.

MacIvor, M. (1995). Redefining science education for Aboriginal students. In M. Battiste \& J. Barman (Eds.), First Nations education in Canada: The circle unfolds (pp. 73-98). Vancouver, BC: UBC Press.

MacNaughton, G. (2005). Doing Foucault in early childhood studies: Applying poststructural ideas. New York, NY: Routledge.

Muir, N., \& Bohr, Y. (2014). Contemporary practice of traditional Aboriginal child rearing: A review. First Peoples Child and Family Review, 9(1), 66-79.

Nguyen, M. (2011). Closing the education gap: A case for Aboriginal early childhood education in Canada: A look at the Aboriginal Head Start program. Canadian Journal of Education, 34(3), 229-248.

Preston, J., Cottrell, M., Pelletier, T., \& Pearce, J. (2011). Aboriginal early childhood education in Canada: Issues of context. Journal of Early Childhood Research, 10(1), 3-18.

Rinaldi, C. (2012). The pedagogy of listening: The listening perspective from Reggio Emilia. In C. Edwards, L. Gandini, \& G. Forman (Eds.), The hundred languages of children (pp. 233-246). Santa Barbara, CA: Praeger.

Truth and Reconciliation Commission of Canada. (2015). Truth and Reconciliation Commission of Canada: Calls to action. Retrieved from: http://www.trc.ca/websites/trcinstitution/File/2015/Findings/Calls_to_Action_English2.pdf 